\title{
Study of Core Material Sandwich Panel In Ship Construction
}

\author{
Edy Utomo ${ }^{1}$, Achmad Zubaydi ${ }^{1}$, and Pompy Pratisna ${ }^{2}$
}

\begin{abstract}
Sandwich panel in ship construction necessitates identification for the core material. Non-metal cores of sandwich materials were identifiedin this study for polyurethane foam, polyresin, and synthetic resin. This material identification was conducted through experiments using Det Norske Veritas (DNV) standard tests. The experiments conducted were reactivity test, density test, and tensile test. Results of the investigation show that the core material suitable for the sandwich panel is synthetic resin with composition of $50 \%$ resin, $50 \%$ talc and $0.3 \%$ catalyst. The density of the material is $1,728 \mathrm{~kg} / \mathrm{m}^{3}$, tensile strength is 24.75 Mpa, modulus of elastisity is $546.95 \mathrm{Mpa}$, and shear modulus is 273.48 Mpa.
\end{abstract}

Keywords-Composite material, Polyresin, Polyurethane foam, Sandwich material, Synthetic resin.

\section{INTRODUCTION}

The application of advanced material development in shipping industry is very rapid. Such as the application of composite sandwich material that consist of two material which has different characteristic. One of the advanced material is SPS (Sandwich Plate System) in ship construction.

Moomcilovic and Motok [1] define SPS is a light material made of two metal plates which separated by polyurethane elastomer core material. Metal plate bonded with bar parimeter at the edge and polyurethane is injected. So this material called composite which consist of two different material, metal and non metal.

Intelligent engineering, Ltd [2] stated that the application of SPS material has been widely used in civil construction or ship construction. The example is Passenger Sea Princess with size (8-20-existing) at the top tanks plating and DSME RORO vessel with size (625 -existing) to reduce noise and vibration in the engine room.

The use of sandwich material in ship construction given a reduce of weight ship construction and given a simple shape of construction, because the interaction between the stiffeners and plate is reduced. Brooking and Kennedy [3] has conducted comparison of weight ship reduction in tanker. Results of comparison is the weight of tanker reduce is $2.8 \%$, so that reduce of several work of manufacture tanker, such as welding $57 \%$ with reduce of stiffeners interactions $97 \%$.

Baidowi and Utomo [4] has conducted FE simulation the use of SPS at inner bottom construction bulk carier 11,000 DWT to replace the use of steel, results of the simulation is the use of SPS provide improved payload

${ }^{1}$ Edy Utomo and Achmad Zubaydi are with Departement of Naval Architecture, Institut of Technology Sepuluh Nopember, Surabaya, Indonesia. E-mail: edyutomo99@gmail.com; zubaydi@na.its.ac.id.

${ }^{2}$ Pompy Pratisna is with Chemical and Materials Laboratory. DISLITBANGAL MABESAL, Surabaya, Indonesia. E-mail: pompypratisna@gmail.com
1,148 ton or can be expressed provide a weight reduction is $13,05 \%$.

The use of SPS can not be applied to the national ship industry, because of the unavailability of raw materials as a core material, so several research to find a replacement of core material is conducted. Utomo and Baidowi [5] has conducted experiment of sandwich panel construction with multiplex panel and polyurethane foam. The research results show that, the sandwich panel is made still can not be used on the main structure of the ship.

Based on these, this study focused to choose the substitute material for polyurethane elastomer as core material. The substitute material is the material which commonly used in the ship construction industry such as polyurethane foam, polyresin and synthetic resin. This study is one part of the use of sandwich panel material for ship construction, where the core material with the standard of the best value will be used as a core material in the manufacture of sandwich panels.

In this study materials used are polyurethane foam, polyresin and synthetic resin with the combination of each. The polyurethane foam is a foam shape material from reaction of polyol and isosyanat material. this material often be used as a heat insulation and sound insulation in the cargo compartment. While polyresin and synthetic resin is a reaction of polyol, resin and talc materials with catalyst for hardeners.

The third form of material is different. Polyurethane foam produce material in foam shape, while polyresin and synthetic resin produce material in solid shape, but the polyresin has a softer shape than the synthetic resin. In the shiping industry, resin is used as a adhesive material for a boat with fibre reinforced plastic material.

\section{METHOD}

Identification are conducted by experiments based on test and criteria which has been set by DNV. First identification is reactivity test to determine the reaction time of core material. DNV [6] give acceptance criteria for reactivity time of core material is $\geq 720$ second. Reactivity time of core material is a time of transformation of raw material from liquid to solid shape. The purpose of identification is to find out how long reactivity time and changes of resulting conditions of core material, possible or impossible the material used as a core material.

In this identification produce time reactivity, change of volume material and physical shape of material. Saveral raw material used for core material is polyol and isosyanat for polyurethane foam shape. Polyol, resin and catalyst for polyresin shape. Resin and catalyst for synthetic resin A shape. Resin, talc and catalyst for synthetic resin B shape. The composition of core material shown as :

1) Polyurethane foam $A=1$ polyol : 1 isosyanat. 
The $2^{\text {nd }}$ International Seminar on Science and Technology August $2^{\text {nd }} 2016$, Postgraduate Program Institut Teknologi Sepuluh Nopember, Surabaya, Indonesia

2) Polyurethane foam $B=1$ polyol : 1.5 isosyanat.

3) Polyurethane foam $\mathrm{C}=1$ polyol : 2 isosyanat.

4) Polyurethane foam $\mathrm{D}=1$ polyol : 2,5 isosyanat.

5) Polyresin $\mathrm{A}=50 \%$ polyol $+50 \%$ resin $+0.3 \%$ catalyst.

6) Polyresin $\mathrm{B}=30 \%$ polyol $+70 \%$ resin $+0.3 \%$ catalyst.

7) Polyresin $\mathrm{C}=20 \%$ polyol $+80 \%$ resin $+0.3 \%$ catalyst.

8) Synthetic resin $A=100 \%$ resin $+0.3 \%$ catalyst

9) Synthetic resin $\mathrm{B}=50 \%$ resin $+50 \%$ talc $+0.3 \%$ catalyst.

Second identification is a density test to find density of core materials. DNV [6] give a standardization test use ISO 845 with acceptance criteria value $\geq 1,000 \mathrm{~kg} / \mathrm{m}^{3}$. Minimum specimen for density test is 5 specimens with volume not less than $100 \mathrm{~cm}^{3}$. Density of core material calculated by equation (1) :

$\rho=m / V \cdot 10^{6}$

where :

$m \quad$ = Mass of sandwich panel, (gram)

$V \quad=$ Volume of specimens, $\left(\mathrm{cm}^{3}\right)$

$\rho \quad=$ Density of sandwich panel, $\left(\mathrm{kg} / \mathrm{m}^{3}\right)$

Third identification is a strength of core material. Identification use a tensile test to find value of strength of core material. DNV [6] give a standardization tensile test use ASTM D 412 and EN 10002 for specimen shape. Shape of specimen shown in Figure 1. where :

$F=$ Tensile load, $(\mathrm{N})$

$A=$ Cross section area of specimen or $S_{0},\left(\mathrm{~mm}^{2}\right)$

$\sigma_{t k}=$ Tensile strength of core material, (Mpa)

Tensile modulus of core material calculated by equation (3) :

$E=\sigma / \varepsilon$

where :

$E=$ Tensile modulus of core material, $(\mathrm{Mpa})$

$\sigma=$ Maximum stress of core material, (Mpa)

$\varepsilon=$ Strain of core material in tensile condition.

Shear modulus of core material calculated by equation (4) :

$G=E /(2(1+v))$

where :

$G=$ Shear modulus of core material, (Mpa)

$E=$ Tensile modulus of core material, $(\mathrm{Mpa})$

$v$ = Poisson ratio, (zero for brittle material)

Testing of strength material for all composition use UTM (Universal Testing Machine) with maximum capasity load 100 ton, in chemical and materials laboratory, department of research and development marine army Indonesia. DNV [6] give a value acceptance criteria of core material. Tensile strength $>5$ Mpa, for tensile modulus $>200 \mathrm{Mpa}$ and shear modulus

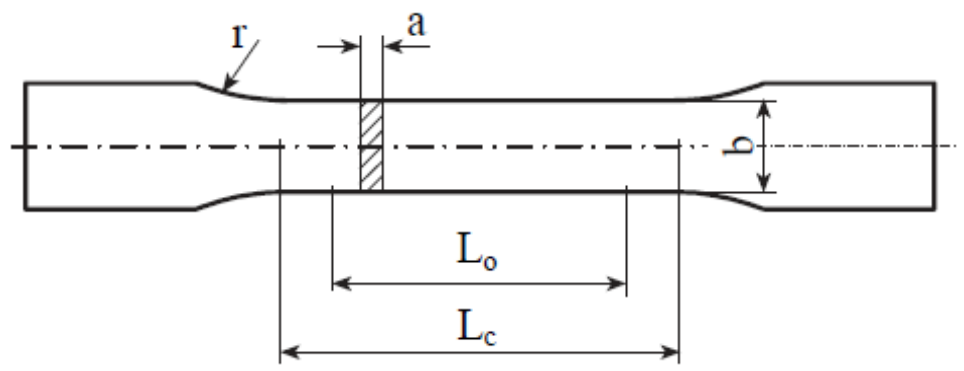

Figure. 1.Specimen shape for tensile test core material. (ASTM D 412 and EN 10002 standard test)

Where :

$a \quad=$ Thickness of core material specimen, $(\mathrm{mm})$

$b \quad=$ Width of core material specimen, $(\geq 25 \mathrm{~mm})$

$L_{0} \quad=$ Length of the initial measurement, $(200 \mathrm{~mm})$

$L_{c} \quad=$ Length of field specimen tested, $(225 \mathrm{~mm})$

$S_{0} \quad=$ Cross section area of spesimen, $(a \times b)$

$r \quad=$ Radius at the end of the field specimen, $(25 \mathrm{~mm})$

Strength of core material expressed as a tensile stress of core material. Tensile stress core material calculated by equation (2) :

$\sigma_{t k}=F / A$ minimum $120 \mathrm{Mpa}$ at minimum specimen is 5 specimens.

Manufacture specimen of all core material has conducted with similary method, where core material be made with mixing raw materials, in accordance with the each composition. Raw material mixed first before being put on a mold in the shape of a square with a thickness of $10 \mathrm{~mm}$. After the casting process, followed by the work of making specimens includes cutting and smoothing specimen, to get the shape as shown in Figure 1.

Environmental conditions of manufacture core material specimens, should be clean and has a normal temperature, between $25-30^{\circ} \mathrm{C}$. Maker specimens should be use goggles and gloves to protect themselves from the reaction in the core material, because reaction of core 
material will produce heat which can lead to sick if exposed to the skin.

The manufacture specimen is done in steps, the first step performed on identification of polyurethane foam material, with several combination of raw materials. Then continued on identification of polyresin and synthetic resin.

\section{RESULTS AND DISCUSSION}

\section{A. REACTIVITYTEST.}

Reactivity test conducted of every types of core material. Purpose this test to know time and condition of core material. The following are shown results of reactivity test in Table $\mathbf{1}$.

Based on information that showing in Table 1, for core material in foam shape, different composition given change of volume material, although every composition give similary time reactivity value. Polyurethane foam A is a composition from comparison 1 polyol and 1 isosyanat produce volume greather than if compared with polyurethane foam B, C and D. Change of volume showing that increase of isosyanat composition will reduce of bond between foam material.

Increase of isosyanat will continue to produce reduce experience change of volume, however give a different physical shape, such as polyresin A and polyresin B, showing impossible for use as core material, because polyresin A and B cannot withstand the self weight. While polyresin $\mathrm{C}$, synthetic resin $\mathrm{A}$ and $\mathrm{B}$ give shape results hard and solid, without a change in volume.

Based on results reactivity test, all type of core material can be use as a core material in layer of sandwich panel material, because value of time reactivity more than standard reactivity value set by DNV. However, base on physical observation there are 2 types of core material that is polyresin A and B (No.5 and 6 in Table 1) which cannot be use, because physical condition results showing inability for withstand the self weight. Then the next identification only conducted at 7 types of core material, that is polyurethane foam A, B, C, $\mathrm{D}$ and polyresin $\mathrm{C}$, synthetic resin $\mathrm{A}$ and $\mathrm{B}$.

\section{B. Desnity test.}

Base on results reaktivity test of core materials, the next investigation only conducted in 7 types of core material to know characteristic value of density core material. Investigation results of density test shown in

\section{Table 2.}

Base on results that showing in Table 2, all density value for core material in foam shape cannot suitable TABLE 1 .

REACTIVITY TEST RESULTS OF EVERY TYPES OF CORE MATERIAL

\begin{tabular}{ccccc}
\hline \hline No & Core type & $\begin{array}{c}\text { Reactivity } \\
\text { time }\end{array}$ & Change of volume & Physical condition \\
\hline 1 & Polyurethane foam A & 900 seconds & $12 \mathrm{ml} \rightarrow 358 \mathrm{ml}$ & Liquid $\rightarrow$ Soft foam \\
2 & Polyurethane foam B & 900 seconds & $15 \mathrm{ml} \rightarrow 356 \mathrm{ml}$ & Liquid $\rightarrow$ Solid foam \\
3 & Polyurethane foam C & 900 seconds & $18 \mathrm{ml} \rightarrow 307 \mathrm{ml}$ & Liquid $\rightarrow$ Solid foam \\
4 & Polyurethane foam D & 900 seconds & $21 \mathrm{ml} \rightarrow 250 \mathrm{ml}$ & Liquid $\rightarrow$ Solid foam \\
5 & Polyresin A & 6 hours & Still condition & Liquid $\rightarrow$ Soft \\
6 & Polyresin B & 6 hours & Still condition & Liquid $\rightarrow$ Soft solid \\
7 & Polyresin C & 6 hours & Still condition & Liquid $\rightarrow$ Solid \\
8 & Synthetic resin A & 6 hours & Still condition & Liquid $\rightarrow$ Solid \\
9 & Synthetic resin B & 6 hours & Still condition & Liquid $\rightarrow$ Solid \\
\hline \hline
\end{tabular}

of volume, such as polyurethane $\mathrm{C}$ which has smaller volume value $13.7 \%$ from polyurethane $\mathrm{B}$ and polyurethane $\mathrm{D}$ has smaller volume value $30.16 \%$ from polyurethane A. This will give change of density and strength value foam material, which are caused by different of bond area in foam material, so that produce different volume of air cavities.

Different with solid core materials condition, that is polyresin and synthetic resin. All solid core material not with standard value of density set by DNV. If further review, types of polyuethane foam give different value of density, this is caused by increase of isosyanat liquid in composition mixing polyurethane foam.

Different with condition of solid core material shape, that is polyresin $\mathrm{C}$, synthetic resin A and B give density value more than acceptance criteria value (> 1.000 $\left.\mathrm{kg} / \mathrm{m}^{3}\right)$. Based on density test, type of core material that can use as core material sandwich panel is a type of solid

TABLE 2.

DENSITY TEST RESULTS OF EVERY TYPES OF CORE MATERIAL

\begin{tabular}{cccc}
\hline \hline No & Core type & $\begin{array}{c}\text { Average density } \\
\left(\mathrm{kg} / \mathrm{m}^{3}\right)\end{array}$ & Criteria control \\
\hline 1 & Polyurethane foam A & 29.00 & $\mathbf{x}$ \\
2 & Polyurethane foam B & 44.00 & $\mathbf{x}$ \\
3 & Polyurethane foam C & 58.00 & $\mathbf{x}$ \\
4 & Polyurethane foam D & 80.00 & $\sqrt{ }$ \\
5 & Polyresin C & $1,175.00$ & $\sqrt{ }$ \\
7 & Synthetic resin A & $1,215.00$ & $\sqrt{ }$ \\
\hline \hline
\end{tabular}


material, that is polyresin $\mathrm{C}$, synthetic resin $\mathrm{A}$ and $\mathrm{B}$.

C. Strength test.

Determination of strength core materials conducted with tensile test material. Polyurethane foam material which does not pass in density test also tested to determine value of its strength. Results of strength polyurethane foam showing in Table $\mathbf{3}$ and Figure $\mathbf{2}$ as follows.

Table 3 shows value of tensile strength polyurethane foam cannot suitable acceptance criteria value set by $\mathrm{DNV}$, because tensile strength of polyurethane foam in every concentration has value lower than acceptance criteria value, with average value is $0.22 \mathrm{Mpa}$. Figure 2 showing comparison of tensile strength polyurethane foam material in every concentration. Base on Figure 2, polyurethane foam with concentration 1 polyol : 2.5 isosyanat with density $80 \mathrm{~kg} / \mathrm{m}^{3}$ has tensile strength more than with other concentrations, with value of tensile strength between $0.30-0.39 \mathrm{Mpa}$ in ultimate load between $53-61$ Newton. While lowest strength value occurs on polyurethane foam with concentration 1 polyol for every composition.

Different with results strength test for solid core material, that is polyresin $\mathrm{C}$, synthetic resin $\mathrm{A}$ and synthetic resin B. Based on results tensile test of solid core materials, strength of polyresin $\mathrm{C}$ is $16.89 \mathrm{Mpa}$, tensile modulus is $164.67 \mathrm{Mpa}$ and elongation of polyresin is $10.25 \%$. Needs strength of core material suitable with acceptance criteria is $20 \mathrm{Mpa}$, this shows that polyresin $\mathrm{C}$ cannot use as a core material in sandwich panel material. The synthetic resin A has a tensile strength $35.95 \mathrm{Mpa}$, tensile modulus $327.21 \mathrm{Mpa}$ and elongation $10.99 \%$, synthetic resin A can use as a core material, because value of strength material more than strength value given by acceptance criteria value, but the physical condition of failure shape material showing fractions, this shows that imposible synthetic resin A used as a core material, because there will be cracks on the sandwich panel made.

The use of $50 \%$ talc material in composition synthetic resin $\mathrm{A}$, called with synthetic resin $\mathrm{B}$ give reduce of failure fraction in synthetic resin, such as shown in

TABLE 3.

TEBSILE TEST RESULTS OF POLYURETHANE FOAM MATERIALS

\begin{tabular}{cccccc}
\hline \hline No & $\begin{array}{c}\text { Type of polyurethane } \\
\text { foam }\end{array}$ & $\begin{array}{c}\text { Tensile strength } \\
(\mathrm{Mpa})\end{array}$ & $\begin{array}{c}\text { Tensile modulus } \\
(\mathrm{Mpa})\end{array}$ & $\begin{array}{c}\text { Elongation } \\
(\%)\end{array}$ & $\begin{array}{c}\text { Criteria } \\
\text { control }\end{array}$ \\
\hline 1 & Polyurethane foam A & 0.0947 & 1.341 & 7.246 & $\mathbf{x}$ \\
2 & Polyurethane foam B & 0.2027 & 3.434 & 6.069 & $\mathbf{x}$ \\
3 & Polyurethane foam C & 0.2483 & 4.828 & 5.254 & $\mathbf{x}$ \\
4 & Polyurethane foam D & 0.3329 & 5.533 & 6.004 & $\mathbf{x}$ \\
\hline \hline
\end{tabular}

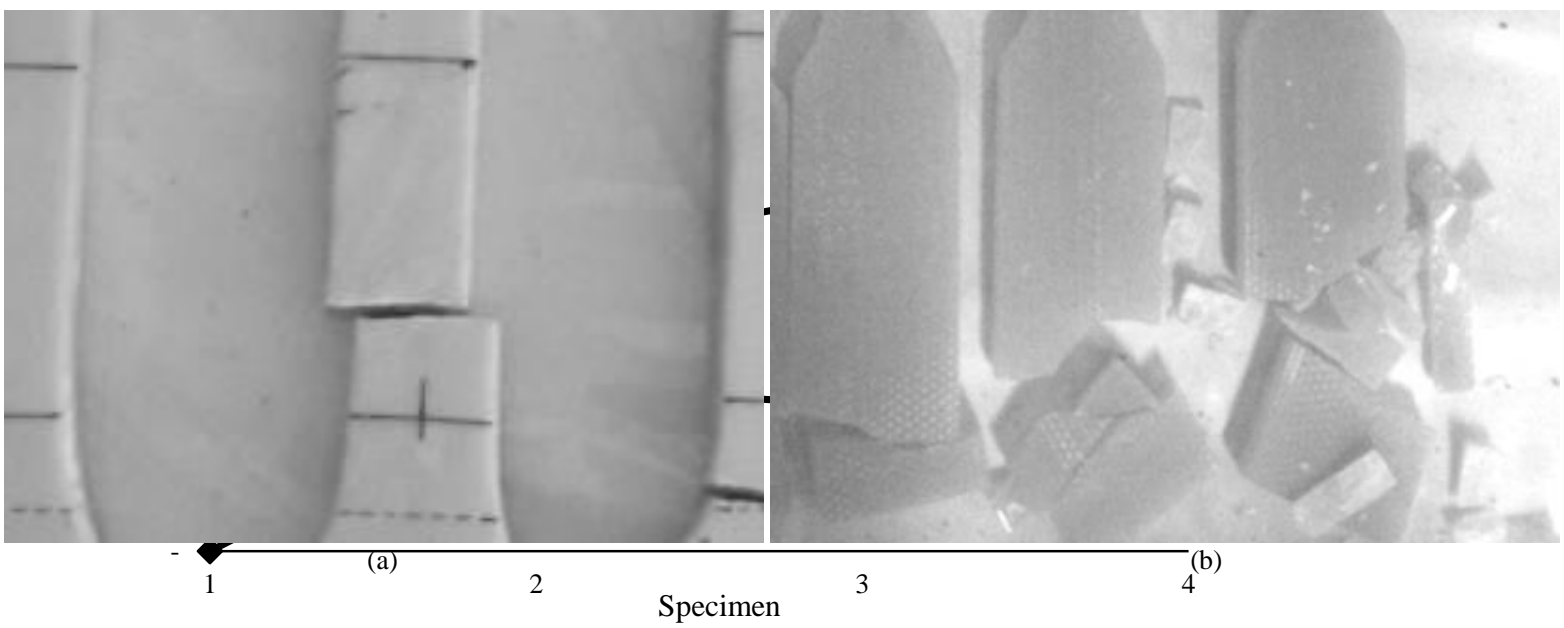

Figure. 3. Shape of failure solid core material

(a) synthetic resin B with 50\% talc in composition, (b) synthetic resin A with $100 \%$ resin in composition Figure. 2. Tensile strength comparison polyurethane foam materials

: 1 isosyanat, with the tensile strength value between $0.04-0.13 \mathrm{Mpa}$ in ultimate load 6-22 Newton.

Based on results investigation, can be conluded that, the higher density value of polyurethane foam material give the best of tensile strength material, because dimension of bond foam that produce smaller, so that will give number of bonds more in level similary volume
Figure 3. The strength of synthetic resin B is $24.75 \mathrm{Mpa}$, tensile modulus $546.95 \mathrm{Mpa}$ and elongation is $10.10 \%$. Based on result of strength value, the synthetic resin B can use as a core material in sandwich panel material, because all value of strength material more than acceptance criteria set by DNV. Results all of strength test solid core material shown in Table 4. 
TABLE 4.

TEBSILE TEST RESULTS OF SOLID CORE MATERIALS

\begin{tabular}{rccccc}
\hline \hline No & $\begin{array}{c}\text { Type of polyurethane } \\
\text { foam }\end{array}$ & $\begin{array}{c}\text { Tensile strength } \\
(\mathrm{Mpa})\end{array}$ & $\begin{array}{c}\text { Tensile modulus } \\
(\mathrm{Mpa})\end{array}$ & $\begin{array}{c}\text { Elongation } \\
(\%)\end{array}$ & $\begin{array}{c}\text { Criteria } \\
\text { control }\end{array}$ \\
\hline 1 & Polyresin C & 16.89 & 164.67 & 10.25 & $\mathbf{x}$ \\
2 & Synthetic resin A & 35.95 & 327.21 & 10.99 & $\sqrt{ }$ \\
3 & Synthetic resin B & 24.75 & 546.95 & 10.10 & $\sqrt{ }$ \\
\hline \hline
\end{tabular}

The core material of synthetic resin A is not selected because of excessive crack that cause fatal demage, although the entire value of strength material in accordance with the value criteria. The crack in the material synthetic resin $\mathrm{A}$ is caused by the absence of binding material in the liquid resin, so that the heat reactivity is not damped and produce small crack until the material harden, its causes fatal demage to the material. Giving talc on the composition of the mixture of resin capable of removing crakcs that occur in the material and increase the strength of the material, although provides increased density of material $27.95 \%$.

The selection of core material conducted on synthetic resin B with composition is 50\% resin : $50 \%$ talc and $0.3 \%$ catalyst for hardner. The mechanical properties of material synthetic resin B shown in Table 5.

Additional considerations change of synthetic resin $\mathrm{B}$ as a core material in sandwich panel is a shape failure of material.

Properties material that use as a core material has a brittle material, because not occur necking down process or change in lateral deformation when through yielding point of the test.

When compared with polyurethane elastomer as a core material in SPS, the synthetic resin B not better than polyurethane elastomer. This is because polyurethane

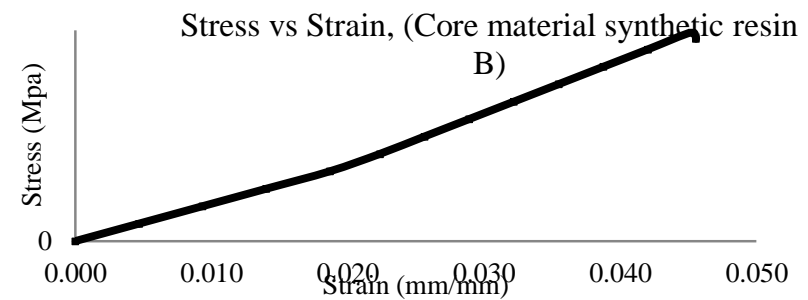

Figure 4. Graph of stress and strain synthetic resin B as a core material

A graph of stress and strain of synthetic resin B are shown in Figure 4.

Figure. 4 Showing graph of stress and strain core material synthetic resin $\mathrm{B}$ with talc raw material in composition mix. The graph show that the material is a brittle material, because of the absence of a clear position yielding point and material failure occurs in the linear region of the curve, which shows that the load has been fully absorbed in the material in these condition.

In addition, the strain that occurs in the material is also very small, which shows the axial deformation that occurs is very low compared with the elastic material that has a greater axial deformation.

\section{CONCLUSION}

Based on analysis results of investigation are

TABLE 5 .

MECHANICAL PROPERTIES OF SYNTHETIC RESIN B AT ROOM TEMPERATURE

\begin{tabular}{lccc} 
& MECHANICAL PROPERTIES OF SYNTHETIC RESIN B AT ROOM TEMPERATURE \\
\hline \hline & \multicolumn{1}{l}{ Mechanical properties synthetic resin at room temperature } & \\
\hline Force yield & $2,140.63 \mathrm{Newton}$ & Max displacement & $4.25350 \mathrm{~mm}$ \\
Yield strength & $8.84556 \mathrm{Mpa}$ & Max Elongation & $4.52500 \%$ \\
Yield displacement & $1.87900 \mathrm{~mm}$ & Elastisity modulus & $2,792.06 \mathrm{Mpa}$ \\
Elongation at yield & $1.99894 \%$ & Shear modulus & $1,396.03 \mathrm{Mpa}$ \\
Force Max & $5,989.38 \mathrm{Newton}$ & Poisson ratio & 0 \\
Tensile strength & $24.7495 \mathrm{Mpa}$ & Density & $1,728 \mathrm{~kg} / \mathrm{m}^{3}$ \\
\hline \hline
\end{tabular}

elastomer has a elastic properties. So, be required other raw material in composition synthetic resin $\mathrm{B}$ for repairing brittle properties in synthetic resin B. Repairing properties

of synthetic resin B can be done with increase liquid rubber in composition mix to get elastic properties. But, that matter should consider with interaction core material and face plate material used. conducted in every types of core material, it can be concluded as follows :

1) Polyurethane foam material with every concentration or composition cannot used as a core material in sandwich panel layer, because all characteristics value of material cannot suitable with acceptance criteria set as by DNV 2012.

2) Solid core materials, such as polyresin and synthetic resin. Synthetic resin better than polyresin, because synthetic resin is more suitable with acceptance criteria and the type of synthetic resin with best result is synthetic resin $\mathrm{B}$.

3) Synthetic resin A has higher strength value, but 
experience crack shape load effect is a fraction failure and it will give the problem of demage to the sandwich panel manufacturing process, so this material is not chosen.

4) Synthetic resin B that has combination for $50 \%$ resin, $50 \%$ talc and $0.3 \%$ catalyst, showing characteritics value of material more than acceptance criteria set as by DNV. Beside that, the shape of damage can be reduced by the addition of raw material talc in mix combination of synthetic resin.

5) Identification of core material elastic types is needed, for repair brittle properties of synthetic resin $\mathrm{B}$, such as the use of rubber materials in the core material composition.

\section{ACKNOWLEDGEMENTS}

During the execution of this study are many parties who have helped, for that thanks be given to :

1) Sandwich panel research team : Ir. Agung Budipriyanto. M.Eng., Ph.D, Septia Hardy Sujiatanti, ST., MT, Indra Hary Winahyu, ST, Windra Iswidodo, ST.

2) Kolonel Laut (T) Ir. Soegeng Poerwadi, Letkol Laut (KH) Drs. Imbalo P. Tambunan and all staff in Chemical and Materials Laboratory, DISLITBANGAL, MABES-AL.

3) Ahmad Baidowi, ST., MT for idea of preliminary study of application sandwich panel in ship construction.

\section{REFERENCES}

[1] Moomcilovic and Motok, "Estimation of ship lightweight reduction by means of application of sandwich plate system,' Faculty of Mechanical Engineering, University of Belgrade, Serbia, 2009.

[2] Intelligent Engineering Ltd, "Overlay tanks top plating in plating ship sea princess", Project Portfolio, IE, UK, 2012.

[3] Brooking and Kennedy, "The performance, safety and production benefits of SPS structures for double hull tankers", Proceedings of the RINA conference on double hull tankers, pp.1-2, London, UK, 22-26, Feb. 2004.

[4] Baidowi and Utomo, "Penggunaan sandwich plate system (SPS) pada konstruksi double bottom", e-journal.undip.ac.id, Vol.12, No.2, 2015.

[5] Utomo and Baidowi, "Preliminary study of sandwich panel application in ship construction : combination of plywood and polyurethane foam material", Proceeding SENTA page 33-38, Faculty of Marine Technology, ITS, Surabaya, Indonesia, 2015.

[6] DNV (Det Norske Veritas), "Steel sandwich pnel construction", Classification notes for ship, No.30, Nov, 2012. 